\title{
复 \\ Repopulação de abrigos de morcegos hematófagos Desmodus rotundus após ações de controle seletivo direto no município de São Pedro - SP
}

\author{
[Repopulation of Desmodus rotundus bat shelters after direct selective control in the municipality \\ of São Pedro - SP]
}

\section{"Artigo Científico/Scientific Article"}

\author{
Paulo Jacques Mialhe*, Luiz Eduardo Moschini
}

Departamento de Ciências Ambientais, Universidade Federal de São Carlos, São Carlos-SP, Brasil.

*Autor para correspondência/Corresponding author: E-mail: paulomialhe@gmail.com

\begin{abstract}
Resumo
Durante o ano de 2002, foi realizada uma busca por abrigos de morcegos hematófagos Desmodus rotundus no município de São Pedro - SP. Quando localizados, essas populações foram georeferenciadas e avaliadas quanto a sua população e utilização. Esses dados foram fornecidos à Coordenadoria de Defesa Agropecuária, a qual enviou uma equipe técnica no dia 08/05/2002 para a realização de um controle populacional através da aplicação de pasta vampiricida. Para a avaliação da repopulação dos abrigos, foram realizadas inspeções nos dias 10/09/2002, 12/04/2005 e 11/05/2006. A repopulação de abrigos foi reduzida de $62,5 \%$ a $87,5 \%$. Quando houve, essa repopulação se deu, principalmente, pela presença de machos em grutas e um túnel. Também foram enviadas amostras de D. rotundus para o Instituto Pasteur - SP, para pesquisa do antígeno rábico e prova biológica, sendo que todas apresentaram resultados negativos. A ausência de repopulação de abrigos por fêmeas e formação de novas maternidades por um período de quatro anos é um indício de que a população de $D$. rotundus está controlada, não ocorrendo crescimento vegetativo da população destes morcegos nesta região. O monitoramento da repopulação dos abrigos por $D$. rotundus, bem como o envio de amostras para pesquisa do antígeno rábico nessa população são importantes ferramentas de estudos de corte epidemiológico do vírus da raiva, além de possibilitar o aprimoramento de estratégias no controle seletivo desses morcegos e da raiva dos herbívoros.
\end{abstract}

Palavras-chave: Desmodus rotundus; abrigos; repopulação; vírus da raiva.

\begin{abstract}
During the year of 2002, a search for shelters containing vampire bats of the Desmodus rotundus species was made in the municipality of São Pedro - SP. When located, the shelters were georeferenced and evaluated for population type and use. These data were provided to the Agricultural Defense Coordination, which sent a technical team on 02/05/2002 and carried out a population control, using warfarine gel. In order to evaluate the repopulation of shelters, reviews were made on 09/10/2002, 04/12/2005, and 05/11/2006. Shelter repopulation was reduced from $62.5 \%$ to $87.5 \%$, and occurred mainly by a few males in caves and a tunnel. D. rotundus samples were also sent to Institute Pasteur - SP, for rabies antigen and biological tests, all of which presented negative results. The absence of repopulation of shelters by females and the formation of new maternities for a period of four years is an indication that the D. rotundus population is controlled, and there is no vegetative growth of the population of these bats in this region. Monitoring repopulation of $D$. rotundus shelters and sending samples for rabies antigen research is important for epidemiological cohort studies of rabies virus and to improve strategies for the selective control of these bats and herbivore rabies.
\end{abstract}

Keywords: Desmodus rotundus; shelters; repopulation; rabies virus 


\section{Introdução}

A ordem Chiroptera é composta por 18 famílias, 202 gêneros e pelo menos 1200 espécies, correspondendo a aproximadamente $\quad 1 / 4$ das espécies de mamíferos. No Brasil ocorrem nove famílias, 65 gêneros e 179 espécies, ocupando todos os domínios morfoclimáticos brasileiros e áreas urbanas (Corrêa et al., 2013). Apenas três espécies de morcegos, todas pertencentes ao Neotropical Família Phyllostomidae, são morcegos que se alimentam de sangue: Desmodus rotundus, Diphylla ecaudata e Diaemus youngi. Enquanto as duas últimas espécies alimentam-se preferencialmente de aves, $D$. rotundus alimentase principalmente de sangue de mamíferos, especialmente cavalos e gado, e ocasionalmente atacam humanos (Hayes e Piaggio, 2018).

Os morcegos estão associados a zoonoses causadas por vários tipos de agentes etiológicos como protozoários, vírus, bactérias e fungos (BRASIL,1998). Morcegos têm sido relatados na literatura infectados por pelo menos 30 espécies de tripanossomatídeos (Molyneux, 1991).

Vírus das famílias Arenaviridae, Bunyaviridae, Coronaviridae, Flaviviridae, Herpesviridae, Orthomyxoviridae, Paramyxoviridae, Picornaviridae, Reoviridae, Rhabdoviridae e Togaviridae têm sido relatados envolvidos em doenças que afetam o homem e animais (Dobson, 2005; Bennett, 2006; Halpin et al., 2007; Kuzmin et al., 2010). Mais de 70 espécies de quirópteros, de 10 famílias, foram identificadas como portadoras desses vírus, responsáveis por muitas doenças infecciosas emergentes (Calisher et al., 2006) causando síndromes respiratórias ou neurológicas graves em humanos e animais podendo levar à morte (Love et al., 2001; Hyatt et al., 2004; Plowright et al., 2011). Na Ásia e Austrália, os vírus Nipah, Hendra e Menangle foram encontrados em quatro espécies de morcegos frugívoros do gênero Pteropus (Pteropodidae) (Corrêa et al., 2013).

Vírus da família Adenoviridae foram isolados em amostras de 23 espécies procedentes de países da Europa e Ásia e também de uma espécie de morcego hematófago, Desmodus rotundus, no Brasil (Lima et al., 2013). Morcegos das famílias Phyllostomidae, Molossidae, e Vespertilionidae são reservatórios do vírus da raiva, uma doença letal para animais humanos e domésticos (Johnson et al., 2014).

Bactérias patogênicas dos gêneros Pasteurella, Salmonella, Escherichia, Yersinia,
Bartonella, Borrelia e Leptospira também foram encontradas em morcegos (Mühldorfer, 2012).

O morcego hematófago $D$. rotundus é uma espécie generalista de habitat com ampla diversidade ecológica e plasticidade tem ampla distribuição no Novo Mundo, ocorrendo desde o norte do México até o norte da Argentina (Barquez et al., 2012). É a espécie mais comum e abundante de morcego hematófago.

Esta espécie habita tocas, cavernas úmidas, pontes e muitas estruturas artificiais, sendo comumente encontrado em habitats antropogênicos (Johnson et al., 2014). Os predadores de $D$. rotundus são principalmente as corujas (Tyto furcata, Athene cunicularia) e serpentes (Elaphe flavirufa, Boa constrictor, Bothrops atrox) (Greenhall et al., 1983). No Brasil foi observado o filostomídeo carnívoro Chrotopterus auritus alimentando-se de um morcego hematófago (Greenhall et al., 1983; Reis et al., 2007).

Em função de seu hábito alimentar e de sua importância econômica devido à transmissão da raiva, é uma das espécies mais bem conhecidas e estudadas do mundo. O modo de nutrição de $D$. rotundus envolve um perigo para a presa e de importância para a saúde pública. Considerando que a perda de sangue não é crítica, pelo menos para a maioria dos animais, a presa é prejudicada pela infecção das feridas com artrópodes e larvas hematófagas e pela transmissão de doenças (Greenhall et al., 1983). As principais doenças são algumas tripanossomíases, a raiva $\mathrm{e}$ a encefalomielite equina venezuelana. Entre os tripanosomas encontrados em $D$. rotundus estão o Trypanosoma cruzi e o $T$. equi, este último responsável pelo "mal das cadeiras" (Rosenthal, 1972).

Além dos prejuízos econômicos diretos causados pela transmissão da raiva, outros danos podem ser citados, como a diminuição da produtividade através dos repetidos ataques, causando debilidade dos animais devido à perda de sangue, infecções secundárias nas feridas, depreciação na pele, oclusão dos canais galactóforos de animais em fase de lactação, entre outras. O prejuízo causado pela espoliação do morcego hematófago pode ultrapassar o prejuízo causado pela mortalidade em consequência da raiva, dado este que merece estudos mais detalhados (Greenhall et al., 1993).

A ocupação do espaço condiciona a forma de comportamento ecológico do transmissor, 
sendo que esse comportamento é dado pela disponibilidade de abrigo e alimento oferecidos (BRASIL, 2009). O desmatamento frequente e a modificação do espaço silvestre reduzem o número de abrigos naturais dos morcegos hematófagos, o que induz à migração dessas espécies para áreas onde haja intensificação da produção pecuária (Reis et al., 2007).

As atividades pecuárias introduzidas pelos colonizadores europeus, e suas consequentes alterações ambientais, proporcionaram condições ideais para a proliferação do $D$. rotundus, como o aumento da oferta de alimentos e novos abrigos, pois os morcegos aproveitam-se de novas habitações criadas pelos homens, como casas abandonadas, túneis, instalações rurais e pontes (Taddei et al., 1991; Kotait et al., 1998, Johnson et al., 2014), levando a disseminação do vírus da raiva em certas áreas rurais (Holmes et al., 2002) e a maior exposição desta zoonose em populações humanas que habitam estas regiões (Fernandes et al., 2013).

A raiva é uma enfermidade de notificação compulsória no país, de acordo com a Portaria 204/2016 do Ministério da Saúde, assim como todos os casos de epizootias, ou seja, doença ou morte de animal ou de grupo de animais que possa apresentar riscos à saúde pública (BRASIL, 2016a). Cabe ao proprietário notificar imediatamente ao Serviço Veterinário Oficial a suspeita de casos de raiva em herbívoros, bem como a presença de animais apresentando mordeduras por morcegos hematófagos, ou ainda informar a existência de abrigos desses morcegos. A não notificação coloca em risco a saúde dos rebanhos da região, podendo expor o próprio homem à enfermidade. Sendo a raiva uma enfermidade de notificação compulsória, caberá sanção legal ao proprietário que não cumprir com esta obrigatoriedade (BRASIL, 2009).

Para que o controle da raiva dos herbívoros seja efetivo, é importante que o Serviço Estadual de Defesa Sanitária Animal mantenha uma rotina de cadastro dos refúgios/abrigos de $D$. rotundus. Os abrigos devem ser georreferenciados com o auxílio de GPS. Nos refúgios frequentados por morcegos hematófagos $D$. rotundus e no caso de suspeita desses morcegos estarem acometidos por raiva, deverão ser coletados espécimes e enviados ao laboratório para fins de diagnóstico.

As equipes que atuam no controle da raiva dos herbívoros devem ter conhecimento pleno da região onde se executam os trabalhos, bem como dos potenciais transmissores que nela habitam. $\mathrm{O}$ método escolhido para o controle de transmissores dependerá da espécie animal envolvida, da topografia e de eventuais restrições legais (áreas de proteção ambiental, reservas indígenas e outras) (BRASIL, 2009).

A Instrução Normativa no 5/2002 do MAPA - Ministério da Agricultura. Pecuária e Abastecimento define as estratégias para o controle da raiva em herbívoros e institui o PNCRH - Programa Nacional de Controle da Raiva dos Herbívoros. A raiva dos herbívoros é controlada pela vacinação de animais em áreas endêmicas e pelo controle das populações de morcegos hematófagos (BRASIL, 2009). Morcegos são animais silvestres protegidos por lei, sendo o manejo e/ou controle regulamentado pela Instrução Normativa do IBAMA n ${ }^{\circ}$ 141/2006 (BRASIL, 2006). A captura de D. rotundus é realizada somente pelos Núcleos de Controle da Raiva do Estado, devidamente capacitados, vacinados contra a raiva (Kotait, 1998; BRASIL, 2009; 2016b).

Esta atividade deverá ser desenvolvida somente nas propriedades em que os coeficientes forem mais expressivos (superiores a 5\%). Excepcionalmente e mediante autorização do IBAMA, poderá ser promovida captura no interior de abrigos naturais. $\mathrm{O}$ método para o controle de morcegos hematófagos está baseado na utilização de substâncias anticoagulantes, especificamente a warfarina. Os métodos de controle devem ser seletivos e executados corretamente, de tal forma a atingir unicamente morcegos hematófagos da espécie $D$. rotundus, não causando danos ou transtorno algum a outras espécies, que desempenham papel importante na manutenção do equilíbrio ecológico na natureza (Kotait et al., 1998, BRASIL 2009).

Os métodos de controle de morcegos hematófagos são classificados em seletivo indireto e direto. O método seletivo indireto é realizado sem o contato com o morcego hematófago, através da aplicação de uma pasta contendo de substâncias químicas anticoagulantes (pasta vampiricida) ao redor da ferida dos animais atacados. A estratégia é fundamentada no hábito do $D$. rotundus utilizar a mesma presa por mais de uma noite seguida para a alimentação, ingerindo assim a pasta vampiricida durante o forrageamento (Lord, 1988; BRASIL, 2009).

O método seletivo direto busca o controle das populações de $D$. rotundus, no qual os 
morcegos hematófagos são capturados nos seus abrigos ou ao redor dos currais, pocilgas, cocheiras, etc., com auxílio de redes próprias e aplicação da pasta vampiricida no dorso de indivíduos que são posteriormente liberados para retornar a sua colônia. Como os morcegos tem o hábito de limparem- se mutuamente (grooming), a pasta vampiricida aplicada leva a eliminação de vários indivíduos na colônia na proporção de um morcego tratado para aproximadamente outros vinte (Lord, 1988; BRASIL, 2009). A avaliação da eficácia do tratamento é feita oito dias depois, através da quantificação da mortalidade dos morcegos nos abrigos ou a redução do coeficiente de mordeduras nos rebanhos (Kotait et al., 1998).

No Estado de São Paulo, observou-se um pico no número de focos de raiva em herbívoros no ano de 1999, com redução drástica a partir de então (BRASIL, 2010). Essa diminuição do número de focos pode ser atribuída à reformulação do modelo de combate à raiva dos herbívoros pela Coordenadoria de Defesa Agropecuária (CDA) da Secretaria de Agricultura e Abastecimento do Estado de São Paulo. Desde 2001. As atividades da CDA incluem formação de equipes treinadas para identificar e caracterizar abrigos de quirópteros, atuação em focos e aceleração do processo coleta-envio-liberação do resultado laboratorial de amostras coletadas em campo. Esse trabalho ocorre na forma de mutirões realizados sistematicamente em regiões problemáticas, na tentativa de cadastrar todos os abrigos de quirópteros e os focos de raiva possíveis, em consonância com as diretrizes do Programa Nacional de Controle da Raiva dos Herbívoros, proposto em 2002 (Dias et al, 2011).

O município de Santa Maria da Serra - SP apresentou um surto de raiva durante o ano de 2000, com a morte de muitos bovinos. Este município é limítrofe com o município de São Pedro - SP, os quais foram incluídos no Programa de Combate a Raiva dos Herbívoros em 2001 e realizado o controle seletivo da população de $D$. rotundus, entre outras atividades relacionadas (Avelino et al., 2005; Souza et al., 2005).

O Planalto Ocidental localizado na região oeste e noroeste do estado de São Paulo, devido a sua topografia pouco acidentada, possui pequena quantidade de abrigos naturais, enquanto a região centro leste do estado de São Paulo é caracterizada como região montanhosa, com topografia acidentada e áreas ainda cobertas pela
Mata Atlântica, onde a quantidade de abrigos naturais ainda é abundante (Taddei et al., 1991).

A participação ativa do $D$. rotundus na transmissão da raiva dos herbívoros é reconhecida há muito tempo, porém muitos aspectos sobre a sua ecologia que seriam de extrema importância para um melhor entendimento sobre a epidemiologia da raiva, ainda permanecem pouco conhecidos. Raros são os estudos longitudinais sobre a dinâmica do vírus da raiva em populações de morcegos. A falta de conhecimento sobre a dinâmica da doença em populações de morcegos limita substancialmente o desenvolvimento de estratégias de controle da raiva nestes animais e na parametrização de modelos de risco para predição da transmissão da doença para humanos e animais domésticos (Calisher et al., 2006). Embora as informações acerca da composição e organização das colônias do morcego hematófago D. rotundus sejam importantes para o controle de suas populações, poucos estudos a esse respeito foram desenvolvidos no Brasil (Bressan et al., 2009).

Enquanto no Brasil um dos pilares do Programa Nacional de Combate da Raiva dos Herbívoros (PNCRH) permanece sendo o controle de morcegos hematófagos através do uso de anticoagulantes, estudos a respeito dos aspectos de imigração, dispersão e comportamento de $D$. rotundus após a realização de controle seletivo direto nas colônias, ainda são raros. Há poucos estudos sobre a revisão de tratamentos com pasta vampiricida em abrigos de D. rotundus e as alterações em sua composição nas repopulações observadas no decorrer do tempo. O monitoramento destas alterações populacionais nos abrigos é importante na percepção da dinâmica populacional destes morcegos numa região e na determinação de estratégias de controle.

O objetivo deste trabalho foi realizar um estudo longitudinal nas repopulações de abrigos de $D$. rotundus no município de São Pedro - SP, após estes serem submetidos ao controle seletivo direto pela equipe da Coordenadoria de Defesa Animal (CDA), a fim de verificar alterações na composição populacional destes morcegos e a presença do vírus da raiva nas colônias destes morcegos.

\section{Material e Métodos}

Durante o período de novembros de 2001 a dezembro de 2002, duas a três vezes por semana, 
foi realizada uma busca por abrigos naturais e artificiais de morcegos hematófagos por todo o município de São Pedro - SP, incluindo todas as propriedades rurais que possuíam rebanhos de herbívoros domésticos.

Quando localizados, estes abrigos foram georreferenciados com um aparelho GPS Garmin etrex ${ }^{\circledR}$ e esses dados foram fornecidos a CDA-SP. Os abrigos receberam tratamento inicial com pasta vampiricida pelos técnicos da CDA'-SP no dia 08 de maio de 2002, e posteriormente realizaram revisões destes abrigos nos dias 10/09/2002, 12/04/2005 e 11/05/2006 para a reavaliação da população nas colônias. Os diferentes intervalos de tempo entre as revisões devem-se as diferentes demandas da equipe técnica pertencente ao sistema de mutirão para o controle de morcegos hematófagos no Estado de São Paulo.

Quando encontrados D. rotundus registrouse o número de morcegos e a utilização do abrigo (maternidade ou abrigo de machos solteiros) e realizou o tratamento com a pasta vampiricida.

Também foram enviadas amostras de $D$. rotundus para o Instituto Pasteur - SP, para exames de imunofluorescência direta (pesquisa do antígeno rábico) e prova biológica.

\section{Resultados}

Durante o período de 28 de novembro de 2001 a 7 de maio de 2002 foram encontrados oito abrigos de morcegos, seis deles habitados com $D$. rotundus. Foi estimada uma população total de 217 D. rotundus distribuídos nos seis abrigos (ID 1, 2, 4, 5, 7 e 8), conforme ilustra a Tabela 1. Dos seis abrigos encontrados, apenas o abrigo 1 - um túnel de água pluvial - era maternidade sendo os abrigos restantes $(83,4 \%)$ habitados por poucos D. rotundus machos, todos em casas abandonadas. Dois abrigos naturais (grutas) encontrados (ID3 e 6) em propriedades rurais, que segundo informações dos proprietários, frequentemente abrigavam colônias de morcegos hematófagos os quais atacavam os bovinos de suas propriedades, haviam recebido tratamento com pasta vampiricida pelos técnicos da CDA-SP no ano de 2000 , sendo que em nenhuma delas foi encontrado D. rotundus.

O abrigo três, localizado na Fazenda Santa Maria (ID 3), é uma gruta arenítica, com uma entrada única, de formato triangular, medido 1,60 $\mathrm{m}$ de altura por $1,80 \mathrm{~m}$ de largura, e alcançando uma profundidade de $4 \mathrm{~m}$, cuja inspeção foi realizada no dia 27/12/2001. Em seu interior nascia uma fonte de água, que formava um lago com $1 \mathrm{~m}$ de profundidade e depois escoava como um pequeno córrego através da propriedade, e estava inabitada.

O abrigo seis localizado no Sitio Rancho Fundo (ID 6), é uma gruta basáltica constituída por vários matacões de granito sobrepostos que formavam um abrigo de apenas uma entrada, encontrada em 19/03/2002. Sua entrada possui aproximadamente $2.5 \mathrm{~m}$ de altura por $2 \mathrm{~m}$ de largura, com um comprimento de aproximadamente $18 \mathrm{~m}$, em linha inclinada para a direita. Não foi encontrado $D$. rotundus na data da inspeção (19/03/2002). Esta gruta estava habitada com espécies de morcegos não hematófagos, entre elas o morcego carnívoro Chrotopterus auritus, que incluem em sua dieta morcegos como $D$. rotundus.

A Tabela 1 mostra o tipo de abrigo, as coordenadas geográficas a utilização do abrigo (maternidade ou abrigo de machos solteiros), e a população encontrada nas datas indicadas em que foi realizado o controle seletivo direto.

Os resultados para a pesquisa de antígeno rábico e prova biológica foram negativos em todos os $D$. rotundus enviados ao Instituto Pasteur.

A localização dos abrigos de morcegos hematófagos (D. rotundus) no município de São Pedro - SP é mostrada na Figura 1.

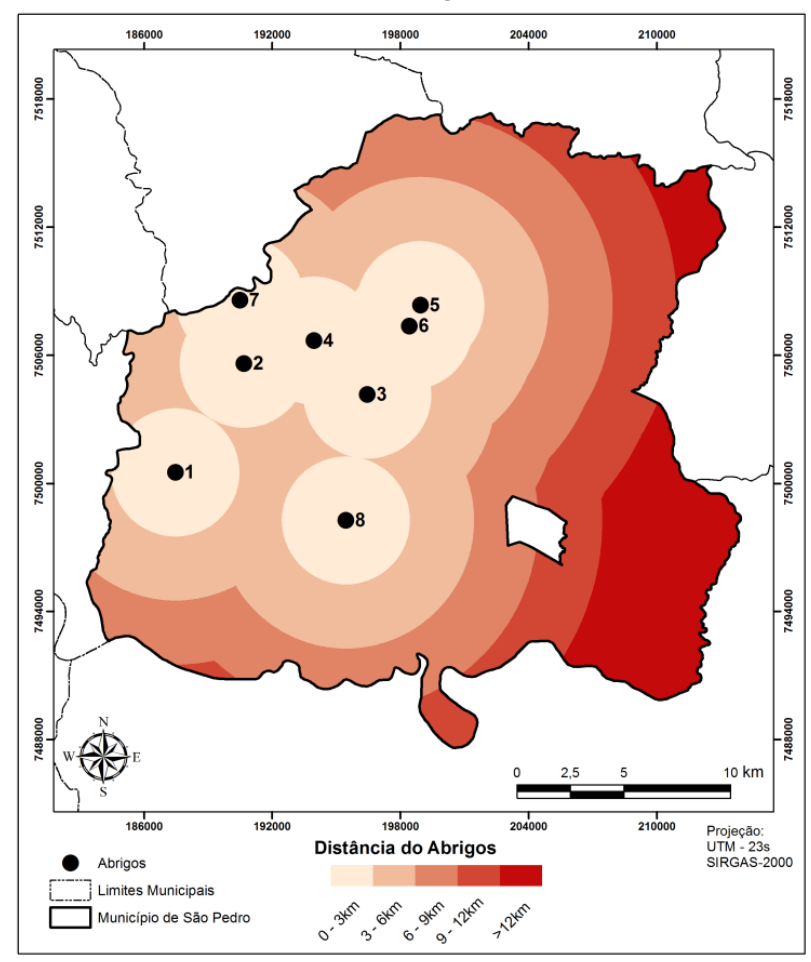

Figura 1. Localização dos abrigos de morcegohematófago (Desmodus rotundus) no município de São Pedro - SP. 
No dia 08 de maio de 2002, uma equipe da CDA realizou o controle seletivo direto nesses abrigos, utilizando pasta vampiricida. Uma semana após a realização do tratamento foram realizadas inspeções nestes abrigos, não sendo encontrado nenhum $D$. rotundus vivo.

Durante o mês de setembro de 2002, todos os abrigos que sofreram controle populacional em maio deste ano foram revisados quanto à existência de D. rotundus. Desses, apenas o abrigo sete foi recolonizado por dois indivíduos machos. Porém, em dois outros abrigos (ID 3 e 6), ambos naturais (grutas), que não estavam habitados por morcegos hematófagos durante a primeira inspeção realizada em maio de 2002, foram encontrados $D$. rotundus. $\mathrm{O}$ abrigo seis, uma gruta basáltica de dimensões médias, abrigava uma colônia maternidade de $D$. rotundus, e o abrigo três, uma pequena gruta arenítica, estava habitado somente por um morcego hematófago macho.

Em 10 de setembro de 2002 os abrigos possuíam uma população total de 103 indivíduos (Tabela 1) que foram tratados com o mesmo produto da aplicação anterior. Uma semana após a realização do tratamento foram realizadas inspeções nestes abrigos, não sendo encontrado nenhum $D$. rotundus vivo.

$\mathrm{Na}$ revisão realizada em 12/04/2005, dos oito abrigos localizados em 2002, somente três abrigos $(1,3,6)$ estavam habitados com $D$. rotundus, sendo todos os indivíduos machos, os quais foram capturados pela equipe da CDA. Na revisão realizada em 11/05/2006, somente dois abrigos (1 e 3 ) estavam ocupados por D. rotundus, também machos.

Tabela 1. Uso, coordenadas geográficas e população de morcegos-vampiro (Desmodus rotundus) nos abrigos do município de S. Pedro - SP.

\begin{tabular}{|c|c|c|c|c|c|c|c|c|c|c|c|}
\hline \multirow[t]{3}{*}{$\begin{array}{c}\text { Identificação do } \\
\text { Abrigo (ID) }\end{array}$} & \multirow[t]{3}{*}{ Tipo } & \multirow[t]{3}{*}{ UTM } & \multirow[t]{3}{*}{ UTM } & \multicolumn{8}{|c|}{$\begin{array}{c}\text { Datas de tratamento nos abrigos, utilização e população } \\
\text { encontrada }\end{array}$} \\
\hline & & & & \multicolumn{2}{|c|}{$08 / 05 / 2002$} & \multicolumn{2}{|c|}{$10 / 09 / 2002$} & \multicolumn{2}{|c|}{$\begin{array}{l}12 / 04 / \\
2005\end{array}$} & \multicolumn{2}{|c|}{$11 / 05 / 2006$} \\
\hline & & & & Pop & Uso & Pop & Uso & Pop & Uso & Pop & Uso \\
\hline 1 & Galeria água & 7500675 & 0804525 & 200 & $\mathrm{M}$ & 0 & --- & 19 & $S$ & 11 & $\mathrm{~S}$ \\
\hline 2 & $\begin{array}{c}\text { Casa } \\
\text { abandonada }\end{array}$ & 7505637 & 807930 & 2 & S & 0 & --- & 0 & --- & 0 & --- \\
\hline 3 & Gruta arenito & 7504165 & 196477 & 0 & --- & 1 & S & 1 & $\mathrm{~S}$ & 1 & --- \\
\hline 4 & $\begin{array}{c}\text { Casa } \\
\text { abandonada }\end{array}$ & 7506686 & 193978 & 1 & S & 0 & --- & 0 & --- & 0 & --- \\
\hline 5 & $\begin{array}{c}\text { Casa } \\
\text { abandonada }\end{array}$ & 7508350 & 198959 & 11 & $S$ & 0 & --- & 0 & --- & 0 & --- \\
\hline 6 & $\begin{array}{l}\text { Gruta natural } \\
\text { basáltica }\end{array}$ & 7507369 & 198440 & 0 & --- & 100 & M & 5 & $S$ & 0 & --- \\
\hline 7 & $\begin{array}{c}\text { Casa } \\
\text { abandonada }\end{array}$ & 7508612 & 0807873 & 2 & $\mathrm{~S}$ & 2 & $S$ & 0 & --- & 0 & --- \\
\hline 8 & $\begin{array}{c}\text { Casa } \\
\text { abandonada }\end{array}$ & 7498267 & 195475 & 1 & $\mathrm{~S}$ & 0 & --- & 0 & --- & 0 & --- \\
\hline
\end{tabular}

Pop = população, $\mathrm{M}=$ maternidade, $\mathrm{S}=$ abrigo de machos solteiros

\section{Discussão}

Apesar da maioria dos abrigos encontrados em maio de 2002 no município de São Pedro serem casas abandonadas, após a realização do tratamento em maio, somente uma casa abandonada foi repopulada por D. rotundus em setembro deste mesmo ano, sendo que os outros abrigos repopulados eram naturais. Os abrigos repopulados em 2005 foram duas grutas (ID $3 \mathrm{e}$ ID 6) e um túnel de água pluvial (ID 1). Em 2006, apenas o túnel de água pluvial e a gruta arenítica (ID 3) estavam habitados por D. rotundus. O túnel 
de água pluvial é um tipo de abrigo artificial que assim como bueiros e furnas, oferece condições de proteção externa, luminosidade, temperatura e umidade semelhante às naturais (grutas), o que poderia favorecer a preferência de colonização deste tipo de abrigo em relação a outros abrigos artificiais mais abertos e expostos a perturbações, tais como pontes, viadutos e torres.

Durante o ano de 2002, no município de São Pedro, $87,5 \%$ dos abrigos que sofreram controle populacional não foram recolonizados por um período de pelo menos quatro meses. Por possuir um olfato bastante desenvolvido e utilizado na comunicação entre os membros do grupo (Turner, 1975), talvez D. rotundus percebam o odor de morcegos mortos nos abrigos onde foram realizados tratamentos com pasta vampiricida, evitando assim recoloniza-los enquanto persistir este odor.

Na revisão em setembro de 2002, o único abrigo recolonizado no município de São Pedro foi o abrigo sete, uma casa abandonada, com dois indivíduos machos. Duas grutas (ID 3 e ID 6), que em maio de 2002 não apresentavam morcegos hematófagos, em setembro deste ano estavam habitadas por $D$. rotundus. A pequena gruta de rocha arenítica da Fazenda Santa Maria (ID 3) estava habitada por somente um indivíduo macho. A gruta de rocha basáltica do Sitio Rancho Fundo (ID 6), de maiores proporções, estava habitada por uma maternidade estimada em 100 indivíduos. Em maio de 2002, esta gruta basáltica abrigava apenas morcegos não hematófagos, sendo que uma das espécies identificada foi o morcego carnívoro Chrotopterus auritus que preda pequenos vertebrados, incluindo $D$. rotundus. Talvez a presença destes morcegos tenha inibido a colonização por $D$. rotundus neste abrigo na época que foi localizado.

A distância entre o abrigo maternidade tratada em maio de 2002 (ID 1) e a nova maternidade localizada em setembro do mesmo ano (ID 6) era de $12,91 \mathrm{~km}$, além do raio de voo comum de 3 a 12 km (BRASIL, 2009; Mialhe e Moschini, 2018), portanto é pouco provável que as fêmeas que colonizaram o ID 6 sejam provenientes do ID 1 . Fêmeas adultas aparentemente escolhem abrigos diurnos em arvores dependendo de quantas outras fêmeas também habitam ali (Turner, 1975). A região no entorno do abrigo seis possui muitas escarpas de difícil acesso com densa cobertura vegetal, podendo haver outros abrigos menores de $D$. rotundus não localizados nas proximidades desta gruta.

Na revisão de 12 de abril de 2005, dos oito abrigos inicialmente habitados em 08/05/2002, apenas três (ID 1,3 e 6) estavam habitados com $D$. rotundus, o que significa uma redução de $62,5 \%$ na utilização destes por um período de quase três anos. Em 11 de maio de 2006, apenas dois abrigos (ID 1 e 3) estavam habitados com $D$. rotundus, aumentando para $75 \%$ a redução de abrigos repopulados por esta espécie, porcentagem próxima aos $72,5 \%$ de abrigos não repopulados após o tratamento seletivo direto encontrada no sudoeste do estado de Minas Gerais (Oliveira et al., 2009).

Nas revisões realizadas durante 2005 e 2006, todos os abrigos tiveram o a população reduzida em relação às revisões anteriores e foram recolonizados somente por $D$. rotundus machos.

Em relação sobre uma possível variação sazonal no número de morcegos durante as estações seca e chuvosos, estudos na região Sudeste indicam que não há variação significativa sobre os eventos de mobilização e armazenamento das reservas energéticas tanto em morcegos hematófagos quanto em não hematófagos, os quais poderiam afetar a população de morcegos encontradas nas colônias. Fatores como abundância e facilidade de acesso a alimentação podem estar contribuindo para a baixa variabilidade sazonal das reservas lipídicas teciduais (Freitas et al., 2006).

Da mesma forma, durante o período de 2002 a 2006 não houve nenhuma alteração ambiental significativa na área de estudo, tal como disponibilidade de água e presas (bovinos). Somente o abrigo cinco - uma casa abandonada foi demolida pelo proprietário em 2003, entretanto os outros abrigos não sofreram nenhuma perturbação.

Suspeita-se que a composição das colônias de $D$. rotundus e sua distribuição no interior dos abrigos diurnos devem interferir na eficiência do controle de suas populações, através da pasta vampiricida de aplicação tópica nos morcegos. Uma colônia dividida em vários subgrupos, vivendo espalhados no interior do abrigo, deve ser mais difícil de eliminar do que uma colônia compacta vivendo em apenas um local do abrigo. Nessa situação, o formato e a estrutura dos abrigos devem influir no formato das colônias. Nas maternidades estudadas no município de São Pedro os morcegos estavam agrupados de forma 
mais homogênea, sem agrupamentos de machos solteiros. As fêmeas devido ao comportamento de compartilhar alimento com outras fêmeas são mais gregárias, mais fiéis ao grupo, e melhores disseminadores de pasta anticoagulante. Já os machos por possuírem comportamentos mais individualizados na colônia, dificilmente compartilham dos comportamentos grupais sendo assim piores disseminadores da pasta e com menor chances de se ingerir pasta anticoagulante, sendo passiveis de escapar do controle seletivo direto. A divisão das colônias dentro dos abrigos, provocada pela estrutura dos mesmos, poderia afetar a eficiência dessa pasta, reduzindo-a sensivelmente (Gomes e Uieda, 2004).

A drástica redução das colônias maternidades implicou na eliminação seletiva de fêmeas, provavelmente levando os machos a se dispersarem a outras regiões em busca de fêmeas para reprodução. Assim, no caso de captura de indivíduos machos, considerando que não são bons disseminadores da pasta vampiricida, parte poderia ser tratada e parte encaminhada para exame laboratorial de raiva para pesquisa da prevalência do vírus rábico. $\mathrm{O}$ uso da pasta vampiricida nos $D$. rotundus machos pode limitar o impacto do tratamento e atingir somente o indivíduo tratado uma vez que, ao retornar da colônia, os machos adultos não sofrerão grooming pelos demais morcegos.

No município de São Pedro - SP, a distribuição mais compacta de $D$. rotundus encontrada nas maternidades (abrigos 1 e 6) pode ter contribuído para a eliminação dessas colônias, principalmente de indivíduos fêmeas e seus filhotes, levando alguns machos que não se contaminaram com a pasta vampiricida a se dispersarem para outras regiões em busca de fêmeas para reprodução. Assim, no caso de captura de indivíduos machos, considerando que não são bons disseminadores da pasta vampiricida, parte poderia ser tratada e parte encaminhada para exame laboratorial de raiva para pesquisa da prevalência do vírus rábico. $\mathrm{O}$ uso da pasta em $D$. rotundus machos pode limitar o impacto do tratamento e atingir somente o indivíduo tratado uma vez que, ao retornar da colônia, os machos adultos não serão lambidos pelos demais (Gomes e Uieda, 2006).

Assim é necessária uma reavaliação dos métodos adotados para o controle de morcegos hematófagos (Gomes et al., 2007) com esforços espacialmente coordenados dirigidos à redução de focos para a eliminação do vírus (Blackwood, 2013). Não há dados comparativos na literatura consultada sobre o intervalo de repopulação considerado nos programas oficiais de controle de populações de morcegos hematófagos comuns. Contudo, mais estudos são necessários para verificar a variação desse intervalo de tempo conforme as regiões geográficas.

\section{Conclusão}

Durante o período de estudo, houve redução no número de abrigos e na população de morcegos hematófagos que os repopularam em relação às revisões anteriores, A mudança no padrão sexual e populacional dos abrigos recolonizados é importante para a reavaliação da vulnerabilidade a raiva nas propriedades próximas aos abrigos. A ausência de repopulação de abrigos por fêmeas e formação de novas maternidades por um período de quatro anos $(2002-2006)$ é um indicio que a população de $D$. rotundus está controlada, não ocorrendo crescimento vegetativo da população destes morcegos nesta região. O monitoramento dos abrigos de D. rotundus e a amostragem de morcegos para a pesquisa do vírus da raiva é importante para estudos epidemiológicos longitudinais da raiva dos herbívoros.

\section{Conflito de Interesse}

interesse.

Os declaram não existir conflito de

\section{Agradecimentos}

Agradeço ao Dr. Vladimir Nogueira, médico veterinário da Coordenadoria de Defesa Agropecuária - SP, pelos dados fornecidos referentes aos anos de 2005 e 2006.

\section{Referências}

Avelino, A.; Zoccolaro, P.T.; Rosa, T.Z.; Cunha, E.M.S. Diagnóstico laboratorial da raiva na região oeste do Estado de São Paulo. Revista da Sociedade Brasileira de Medicina Tropical, 38(6): 493-495, 2005.

Barquez, R.; Pérez, S.; Miller, B.; Díaz, M. Desmodus rotundus. IUCN: International Union for Conservation of Nature, 2012 Disponível em: 〈www.iucn.org〉. Acesso em: 14 jun. 2020.

Bennett, M. Bats and human emerging diseases. Epidemiological Infectious 134: 905-907, 2006. 
Blackwood, J.C. Resolving the roles of immunity, pathogenesis, and immigration for rabies persistence in vampire bats. Proceedings of the National Academy of Sciences, 110(51): 20837-20842, 2013.

BRASIL. Ministério da Saúde. Morcegos em áreas Urbanas e Rurais: Manual de Manejo e Controle. Brasília, 1998. Disponível em: https://pt.scribd.com/doc/72930141/Morcegosem-areas-urbanas-e-rurais-manual-de-manejoe-controle. Acesso em: 14 jun. 2020.

BRASIL, Instituto Brasileiro do Meio Ambiente e dos Recursos Naturais Renováveis. Instrução Normativa $\mathbf{n}^{\mathbf{1}}$ 141, de 19 de dezembro de $2006 . \quad$ Disponível em: <https://portal.fiocruz.br/sites/portal.fiocruz.br/ files/documentos/IN\%20141\%20IBAMA\%20 DEZ\%2006.pdf >. Acesso em: 14 jun. 2020.

BRASIL, Ministério da Agricultura, Pecuária e Abastecimento. Controle da raiva dos herbívoros: manual técnico. Brasília: Mapa/ACS, 2009, p. 43-56. Disponível em: <http://www.agricultura.gov.br/arq_editor/file/ Aniamal/programa\%20nacional\%20dos\%20he rbivoros/revis\%C3\%A3o\%20sobre\%20raiva.p df>. Acesso em: 14 jun. 2020.

BRASIL, Ministério da Agricultura, Pecuária e Abastecimento. Casos de raiva em herbívoros e suínos no Brasil, no período anual de 1996 a 2008. Brasília: MAPA, 2010. Disponível em: <http://www.agricultura.gov.br/arq_editor/file/ Aniamal/programa\%20nacional\%20dos\%20he rbivoros/casos\%20de\%20raiva\%20em\%20her bivoros.pdf>. Acesso em: 14 jun. 2020.

BRASIL, Ministério da Saúde. Portaria n ${ }^{\mathbf{0}}$ - 204, de 17 de fevereiro de 2016a. Disponível em: <http://bvsS.saude.gov.br/bvs/saudelegis/gm/2 016/prt0204_17_02_2016.html>. Acesso em: 14 jun. 2020.

BRASIL, Ministério da Saúde, Secretaria de Vigilância em Saúde, Departamento de Vigilância das Doenças Transmissíveis. Manual de Vigilância, Prevenção e Controle de Zoonoses. 2016b. Disponível em: <http://bvsS.saude.gov.br/bvs/publicacoes/man ual_vigilancia_prevencao_controle_zoonoses.p df>. Acesso em: 14 jun. 2020.

Bressan, P.M.; Kierulff, M.C.M.; Sugieda, M.A. Fauna ameaçada de extinção no estado de São Paulo - Vertebrados. São Paulo: Fundação Parque Zoológico de São Paulo: Secretaria do Meio Ambiente, 2009. 645p.
Calisher, C.H.; Childs, J.E.; Field, H.E.; Holmes, K.V.; Schountz, T. Bats: important reservoir hosts of emerging viruses. Clinical Microbiology Reviews. 19: 531-545, 2006.

Corrêa, M.M.O.; Lazar, A.; Dias, D.; Bonvicino, C.R. Quirópteros hospedeiros de zoonoses no Brasil. Boletim da Sociedade Brasileira de Mastozoologia, 67: 23-38, 2013.

Dias, R.A.; Nogueira Filho, V.S.; Goulart, C.S.; Telles, I.C.O.; Marques, G.H.F., Ferreira, F.; Amaku, M.; Neto, J.S.F. Modelo de risco para circulação do vírus da raiva em herbívoros no Estado de São Paulo, Brasil. Revista Panamericana de Salud Publica, 30(4): 37376, 2011.

Dobson, A.P. What links bats to emerging infectious diseases? Science 310: 628-629, 2005.

Fernandes, M.E.B.; Costa, L.J.; Andrade, F.A.G.; Silva, L.P. Rabies in humans and non-human in state of Pará, Brazilian Amazon. Brazilian Journal Infectious Diseases, 17: 251-253. 2013.

Freitas, M.B.; Welker, A.F.; Pinheiro, E.C. seasonal variation and food deprivation in common vampire bats (CHIROPTERA: PHYLLOSTOMIDAE). Brazilian Journal of Biology, 66(4): 1051-1055, 2006.

Gomes, M.N; Uieda, W. Abrigos diurnos, composição de colônias, dimorfismo sexual e reprodução do morcego hematófago Desmodus rotundus (E. Geoffroy) (Chiroptera, Phyllostomidae) no Estado de São Paulo. Brasil. Revista Brasileira de Zoologia 21(3): 629-638, 2004.

Gomes, M. N.; Uieda, W.; Latorre, M.R.D.O. Influência do sexo de indivíduos da mesma colônia no controle químico das populações do morcego hematófago Desmodus rotundus (Phyllostomidae) no Estado de São Paulo. Pesquisa Veterinária Brasileira. 26(1): 3843, 2006.

Gomes, M.N.; Monteiro, A.M.V.; Nogueira, V.S.; Gonçalves, C.A. Áreas propícias para o ataque de morcegos hematófagos Desmodus rotundus em bovinos na região de São João da Boa Vista, estado de São Paulo. Pesquisa Veterinária Brasileira, 27: 307-313, 2007.

Greenhall, A.M.; Joermann, G.; Schmidt, U. Desmodus rotundus. Mammalian Species, 202: 1-6, 1983.

Greenhall, AM; Artois, M; Fekadu, M. Bats and rabies. Lyon: Marcel Mérieux, 1993.107p. 
Halpin, K.; Hyatt, A.D.; Plowright, R.K.; Epstein, J.H.; Daszak, P.; Campo, H.E.; Wang L.; Daniels, P.W. Henipavirus ecology research group.emerging viruses: coming in on a wrinkled wing and a prayer. Emerging Infectious Diseases, 44: 711-717, 2007.

Hayes, M.A.; Piaggio, A.J. Assessing the potential impacts of a changing climate on the distribution of a rabies virus vector. PLoS One, 13(2), 2018.

Hyatt, A.D.; Daszak, P.; Cunningham, A.A.; Field, H.; Gould, A.R. Henipaviruses: gaps in the knowledge of emergence. EcoHealth, 1: 25-38, 2004.

Holmes, E.C.; Woelk, C.H.; Kassis, R.; Bourhy, H.A. Genetic constraints and the adaptive evolution of rabies virus in nature. Virology, 292(2): 247-257, 2002.

Johnson, N.; Aréchiga-Ceballos, N.; AguilarSetien, A. Vampire bat rabies: ecology, epidemiology and control. Viruses, 6(5): 1911-1928, 2014.

Kotait, I; Gonçalves, C. A.; Peres, N.F.; Souza, M.C.A.M.; Targueta, M.C. Manual Técnico do Instituto Pasteur n. 1 - Controle da raiva dos herbívoros São Paulo, 1998. Disponível em:

<file:///C:/Users/User/Downloads/manual_01 \%20(1).pdf>. Acesso em: 14 jun. 2020.

Kuzmin, I.V.; Mayer, A.E.; Niezgoda, M.; Markotter, W.; Agwanda, B.; Breiman, R.F.; Rupprecht, C.E. Shimoni bat virus, a new representative of the Lyssavirus genus. Virus Research 149(2): 197-210, 2010.

Lima, F.E.S.; Cibulsk, S.P; Carnielli Jr., P.; Elesbao, F.; Batista, H.B.C.R.; Roehe, P.M.; Franco, A.C. First detection of adenovirus in the vampire bat (Desmodus rotundus) in Brazil. Virus Genes 47(2): 378-381, 2013.

Lord, R.D. Control of vampire bats. In: Greenhall, A.M.; Schmidt, U. Natural history of vampire bats. Boca Ratón: CRC Press, 1988. p.215-226.

Love, R.J.; Philbey; A.W.; Kirkland, P.D.; Ross, A.D.; Davis R.J.; Morrissey C.; Daniels, P.W. Reproductive disease and congenital malformations caused by Menangle virus in pigs. Australian Veterinary Journal 79(3): 192-198, 2001.
Mialhe, P.J.; Moschini, L.E. Análise de fatores de receptividade de vulnerabilidade na elaboração de modelo de risco a ataques de morcegos hematófagos a bovinos no município de São Pedro - SP. Archives of Veterinary Science 23(2): 72-83, 2018.

Molyneux, D.H. Trypanosomes of bats. In: Kreier, J.P; Baker, J.R. Parasitic Protozoa. San Diego: Academic Press, 1991. p. 195-224.

Mühldorfer, K. Bats and bacterial pathogens: a review. Zoonoses and Public Health 60(1): 93-103, 2012.

Oliveira, P.R; Silva, D.A.R.; Rocha, J.H.; Melo, S.M.A; Bombonato, N.G.; Carneiro e Silva, F.O. Levantamento, cadastramento e estimativa populacional das habitações de morcegos hematófagos, antes e após atividades de controle, no município de Aráguari, MG. Arquivo do Instituto Biológico 76(4): 553560, 2009.

Plowright, R.K.; Foley, P.; Field, H.E; Dobson, A.P.; Foley, J.E.; Eby, P.; Daszak, P. Urban habituation, ecological connectivity and epidemic dampening: the emergence of Hendra virus from flying foxes (Pteropus spp.). Proceedings of the Royal Society B 278: 3703-3712, 2011.

Reis, N.R.; Peracchi, A.L.; Pedro, W.A.; Lima, I.P. Morcegos do Brasil. Londrina: Nélio R. dos Reis, 2007. 253p.

Rosenthal, J. E. AID finds ways to control vampire bat. War on Hunger 6(60): 1-23, 1972.

Souza, L.C.; Langoni, H.; Silva; R.C.; Lucheis; S.B. Vigilância epidemiológica da raiva na região de Botucatu-SP: importância dos quirópteros na manutenção do vírus na natureza. Ars Veterinaria, 21(1): 62-68, 2005.

Taddei, V.A.; Gonçalves, C.A.; Pedro, W.A.; Tadei, W.J.; Kotai, I.; Arieta, C. Distribuição do morcego vampiro Desmodus rotundus no Estado de São Paulo e a raiva dos animais domésticos. Campinas: Impresso Especial da CATI, 1991. 107p.

Turner, D.C. The vampire bat. A field study in behavior and ecology. Maryland: The Johns Hopkins University Press, 1975. 146p. 